\title{
HIÊUU QUẢ CỦA THỞ ÁP LỰC DƯƠNG LIÊN TỤC QUA MŨI TRONG ĐIỀU TRI SUY HÔ HẤP CẤP Ở TRẺ EM TẠI BỆNH VIỆN NHI TRUNG ƯƠNG
}

\author{
Trần Duy Vũ ${ }^{1}$, Nguyễn Thị Yến ${ }^{1}$, Lê Thị Hồng Hanh ${ }^{2}$
}

\section{TÓM TẮT.}

Mục tiêu: Đánh giá hiệu quả của thở áp lực dương liên tục qua mũi (NCPAPP) bằng van Benveniste trong điều trị suy hô hấp cấp ở trẻ em tại Trung tâm Hô hấp Bệnh viện Nhi Trung ương. Đồi tượng và phương pháp nghiên cứu: Mô tả tiến cứu 31 bệnh nhi suy hô hấp cấp được điều trị bằng phương pháp thở áp lực dương liên tục qua mũi bằng van Benveniste tại Trung tâm Hô hấp Bệnh viện Nhi Trung ương trong thời gian từ 7/2020 đến 6/2021. Kết quả: Tỷ lệ thành công của thở áp lực dương liên tục qua mũi bằng van Benveniste là $61.3 \%$, thời gian thở NCPAP trung bình là 5.23 ngày. Sau 6 giờ thở NCPAP, các chỉ số về khí máu được cải thiện rõ rệt: $\mathrm{PaO}_{2}$ tăng từ $77.98 \mathrm{mmHg}$ lên $110.33 \mathrm{mmH}$, $\mathrm{SaO}_{2}$ tăng từ $87.67 \%$ lên $95.95 \%, \mathrm{PaCO}_{2}$ giảm từ $59.02 \mathrm{mmHg}$ xuống $54.48 \mathrm{mmHg}$, pH tăng từ 7.32 lên 7.37. Tỷ lệ trẻ thở nhanh giảm từ $96.8 \%$ xuống còn $45.2 \%$, tỷ lể trẻ có rút lõm lồng ngực giảm từ $90.3 \%$ còn $58.1 \%$, tỷ lệ trẻ có tím từ $96.8 \%$ giảm còn $35.5 \%$ và tỷ lệ trẻ kích thích hoặc li bì từ $96.8 \%$ giảm còn $22.6 \%$. Kết luân: Thở áp lực dương liên tưc qua mũi bằng van Benveniste có hiệu quả trong việc cải thiện các chỉ số về khí máu cũng như dấu hiệu lâm sàng của suy hô hấp ở trẻ em tại thời điểm sau 6 giờ.

Tư khóa: suy hô hấp cấp, thở áp lực dương liên tục qua mũi, khí máu.

\section{SUMMARY \\ EFFECTIVENESS OF NASAL CONTINUOUS \\ POSITIVE AIRWAY PRESSURE IN THE \\ TREATMENT OF PEDIATRIC ACUTE \\ RESPIRATORY FAILURE AT VIETNAM \\ NATIONAL CHILDREN'S HOSPITAL}

Objective: To evaluate the effectiveness of Nasal Continuous Positive Airway Pressure (NCPAP) via Benveniste valve in the treatment of pediatric acute respiratory failure at the Respiratory Center of Vietnam National Children's Hospital. Subjects and methods: This prospective descriptive study included 31 patients treated for acute respiratory failure by NCPAP at the Respiratory Center of Vietnam Natinonal Children's Hospital from 7/2020 to 6/2021. Results: The success rate of NCPAP was $61.3 \%$, the mean time was 5.23 days. After 6 hours, the arterial blood gas was significantly improved: $\mathrm{PaO}_{2}$ increased from 77.98 $\mathrm{mmHg}$ to $110.33 \mathrm{mmHg}, \mathrm{SaO}_{2}$ increased from $87.67 \%$ to $95.95 \%, \mathrm{PaCO}_{2}$ decreased from $59.02 \mathrm{mmHg}$ to

\footnotetext{
${ }^{1}$ Trường Đại học Y Hà Nội

${ }^{2}$ Bệnh viện Nhi Trung ương

Chịu trách nhiệm chính: Trần Duy Vũ

Email: Duyvug4a3@gmail.com

Ngày nhân bài: 17.6.2021

Ngày phản biện khoa học: 12.8.2021

Ngày duyệt bài: 24.8.2021
}

$54.48 \mathrm{mmHg}, \mathrm{pH}$ increased from 7.32 to 7.37 . The rate of children with tachypnea decreased from $96.8 \%$ to $45.2 \%$, the rate of chest indrawing decreased from $90.3 \%$ to $58.1 \%$, the rate of cyanosis fell from $96.8 \%$ to $35.5 \%$, and the rate of irritability or lethargy dropped from $96.8 \%$ to $22.6 \%$. Conclusion: Nasal Continuous Positive Airway Pressure via Benveniste valve is effective in improving arterial blood gas as well as clinical signs of pediatric acute respiratory failure at the time after 6 hours.

Keywords: acute respiratory failure, Nasal Continuous Positive Airway Pressure, arterial blood gas.

\section{I. ĐĂT VẤN ĐỀ}

Suy hô hấp cấp là tình trạng hệ hô hấp không cung cấp đủ khí oxy $\left(\mathrm{O}_{2}\right)$ và đào thải khí carbonic $\left(\mathrm{CO}_{2}\right)$ phù hợp với nhu cầu chuyển hóa của cơ thểi. Các phương thức thông khí xâm nhập mang lại nhiều cơ hội điều trị suy hô hấp năng ở trẻ em nhưng kéo theo nhiều nguy cơ. Vì vậy, để hạn chế tỉ lệ đặt nội khí quản thở máy, xu hướng can thiệp sớm bằng các biện pháp thông khí không xẩm nhập ngày càng phổ biến trên thế giới và Việt Nam. Gần đây, phương pháp thở áp lực dương liên tục qua mũi (NCPAP) được áp dụng tại Trung tâm hô hấp Bệnh viện Nhi Trung ương, số lượng trẻ phải thở NCPAP cũng khá lớn, điều này đặt ra sự cần thiết về nghiên cứu đánh giá hiệu quả của phương pháp này trong điều trị. Vì vậy chúng tôi tiến hành nghiên cứu với mục tiêu: Đánh giá hiệu quả của thở áp lực dương liên tục qua mưi bằng van Benveniste trong điều trị suy hô hấp cấp của trẻ em tuổi từ 1 tháng đến 12 tháng tại Trung tâm Hô hấp Bệnh viện Nhi Trung ương.

\section{II. ĐỐI TƯợNG VÀ PHƯƠNG PHÁP NGHIÊN CỨU}

1. Đối tượng nghiên cứu. 31 bệnh nhân suy hô hấp cấp được điều trị bằng thở áp lực dương liên tục qua mũi bằng van Benveniste tại Trung tâm Hô hấp Bệnh viện Nhi Trung ương từ $7 / 2020$ đến 6/2021.

Tiêu chuẩn lựa chọn bệnh nhân:

- Tuổi từ 1 tháng đến 12 tháng.

- Có biểu hiện suy hô hấp cấp:

+ Lâm sàng: Thở nhanh: Trẻ dưới 2 tháng tuổi nhịp thở $\geq 60$ lần/ phút. Trẻ từ 2 tháng đến 12 tháng $\geq 50$ lần/ phút.

- Rút lõm lồng ngực.

- Có tím hoăc không tím.

- $\mathrm{SpO}_{2}<95 \%$. 


\section{+ Khí máu:}

- $\mathrm{SaO}_{2}<90 \%$ hoặc $\mathrm{PaO}_{2}<60 \mathrm{mmHg}$ với $\mathrm{FiO}_{2}=21 \%$; và/ hoăc $\mathrm{PaCO}_{2}>50 \mathrm{mmHg}^{1}$.

- Có chỉ định thở NCPAP: Bệnh nhân suy hô hấp đã thở oxy qua mask trong thời gian ít nhất 1 giờ nhưng vần còn biểu hiện suy hô hấp.

\section{Phương pháp nghiên cứu:}

Thiết kế nghiên cứu: mô tả, cắt ngang, tiến cứu.

Phương pháp: Bệnh nhân có chỉ định thở NCPAP được ghi nhận các triệu chứng lâm sàng và làm xét nghiệm khí máu trước và sau khi thở NCPAP 6 giờ. Hiệu quả của thở NCPAP được đánh giá bằng việc so sánh triệu chứng lâm sàng và các chỉ số trong khí máu trước và sau khi thở NCPAP 6 giờ.

Xử lý số liệu: bằng phần mềm thống kê $\mathrm{y}$ học SPSS 22.0

\section{KẾT QUẢ NGHIÊN CỨU}

\section{Kết quả điêu trị chung}

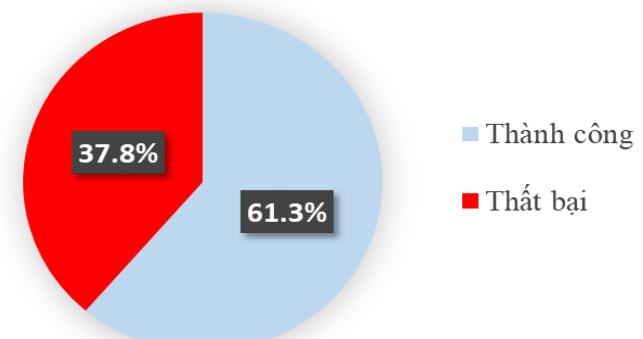

Biểu đồ 1: Til lệ thành công, thât bai của thơ NCPAP

Nhân xét: có 19/31 trường hợp thành công khi thở NCPAP tương ứng 61.3\%. Có 12 trẻ (chiếm $37.8 \%$ ) phải ngừng thở NCPAP để chuyển sang đăt nội khí quản thở máy.

Bảng 1: Thời gian thơ NCPAP trung binh

\begin{tabular}{|c|c|}
\hline Nhóm & Thời gian thở NCPAP (ngày) \\
\hline Nhóm chung & $5.23 \pm 4.75$ \\
\hline Thành công & $7.21 \pm 5.12$ \\
\hline Thất bại & $2.08 \pm 1.00$ \\
\hline
\end{tabular}

Nhận xét: Thời gian thở NCPAP trung bình của nhóm chung là 5.23 ngày. Thời gian thở NCPAP trung bình của bệnh nhân ở nhóm thất bại (2.08 \pm 1.00 ngày) ngắn hơn so với nhóm thành công (7.21 \pm 5.12 ngày) do hầu hết bệnh nhân thất bại với NCPAP đều xảy ra trong vòng 3 ngày đầu.

2. Sự thay đổi các chỉ số khí máu và triệu chứng lâm sàng

Bảng 2: Sự thay đổi các chỉ số trong khí máu sau khi thở NCPAP 6 giò

\begin{tabular}{|l|c|c|c|}
\multirow{2}{*}{ Chỉ số } & \multicolumn{2}{|c|}{ Thời điểm } & \multirow{2}{*}{ p } \\
\cline { 2 - 3 } & Trước thở & Sau thở & \multirow{2}{*}{} \\
\hline
\end{tabular}

\begin{tabular}{|c|c|c|c|}
\hline & NCPAP & NCPAP 6 giờ & \\
\hline $\mathrm{PaO}_{2}$ & $77.98 \pm$ & $110.33 \pm$ & $<0.05$ \\
$(\mathrm{mmHg})$ & 32.85 & 41.73 & \\
\hline $\mathrm{SaO}_{2}(\%)$ & $87.67 \pm$ & $95.95 \pm$ & $<0.05$ \\
\hline $\mathrm{PaCO}_{2}$ & 14.95 & 4.08 & \\
$(\mathrm{mmHg})$ & 13.19 & $54.48 \pm$ & $>0.05$ \\
\hline $\mathrm{pH}$ & $7.32 \pm 0.08$ & $7.37 \pm 0.06$ & $<0.01$ \\
\hline
\end{tabular}

Nhân xét: Sau 6 giờ thở NCPAP có sự thay đổi tích cực về các chỉ số khí máu. Tình trang giảm oxi máu được cải thiện rõ rệt: $\mathrm{PaO}_{2}$ tăng từ $77.98 \mathrm{mmHg}$ lên $110.33 \mathrm{mmHg}(p<0.05), \mathrm{SaO}_{2}$ cũng tăng từ $87.67 \%$ lên $95.95 \%$ một cách có ý nghĩa thống kê $(p<0.05)$. Tình trạng tăng $\mathrm{CO}_{2}$ trong máu được cải thiện một phần: $\mathrm{PaCO}_{2}$ giảm từ $59.02 \mathrm{mmHg}$ xuống còn $54.48 \mathrm{mmHg}$ nhưng không có ý nghĩa thống kê ( $p>0.05)$. Sau 6 giờ thở NCPAP, tình trạng toan hóa máu cũng được giải quyết, $\mathrm{pH}$ máu trung bình từ mức toan hóa (7.32) đã trở về mức bình thường (7.37) $(p<$ 0.01).

Bảng 3: Sư thay đổi về triêu chứng lâm sàng sau khi thơ NCPAP 6 giơ

\begin{tabular}{|c|c|c|c|}
\hline \multirow[b]{2}{*}{ Triệu chứng } & \multicolumn{2}{|c|}{ Thời điểm } & \multirow[b]{2}{*}{ p } \\
\hline & $\begin{array}{c}\text { Trước thở } \\
\text { NCPAP }\end{array}$ & $\begin{array}{c}\text { Sau thở } \\
\text { NCPAP } 6 \text { giờ }\end{array}$ & \\
\hline Thơ nhanh & $96.8 \%$ & $45.2 \%$ & $<0.01$ \\
\hline $\begin{array}{l}\text { Rút lõm lồng } \\
\text { ngực }\end{array}$ & $90.3 \%$ & $58.1 \%$ & $<0.01$ \\
\hline Tím & $96.8 \%$ & $35.5 \%$ & $<0.01$ \\
\hline $\begin{array}{l}\text { Kích thích } \\
\text { hoặc li bì }\end{array}$ & $96.8 \%$ & $22.6 \%$ & $<0.01$ \\
\hline
\end{tabular}

Nhận xét: Sau 6 giờ thở NCPAP, các triẹu chứng lâm sàng của suy hô hấp như thở nhanh, rút lõm lồng ngực, tím, kích thích hoặc li bì từ tî lệ trên $90 \%$ đã giảm một cách rõ rệt $(p<0.01)$.

\section{Các tai biến gặp khi thở NCPAP} Bảng 4: Các tai biến gặp khi thở NCPAP

\begin{tabular}{|c|c|c|}
\hline Loại tai biến & Số bệnh nhân & Tỉ lệ (\%) \\
\hline Phù mặt & 1 & 3.23 \\
\hline Loét mũi & 1 & 3.23 \\
\hline Chướng bụng, nôn & 0 & 0 \\
\hline Tràn khí màng phổi & 0 & 0 \\
\hline Tràn khí trung thất & 0 & 0 \\
\hline
\end{tabular}

Nhận xét: Các tai biến gặp phải do NCPAP đều là các tai biến nhẹ như phù mắt và loét mũi, có tỉ lệ thấp 3.23\%. Chúng tôi không ghi nhân các tai biến nặng như tràn khí màng phổi hay tràn khí trung thất.

\section{BÀN LUÂN}

Thở áp lực dương liên tục là một phương thức hỗ trợ cho trẻ bị suy hô hấp còn khả năng 
tự thở bằng cách duy trì một áp lực dương liên tục trong suốt chu kỳ thở. Từ những năm 1930, CPAP đã được ứng dụng thành công trong điều trị suy hô hấp do tổn thương phổi ở người lớn. Đến năm 1971, Gregory và cộng sự đã công bố báo cáo đầu tiên về hiệu quả của NCPAP trong điều trị hội chứng suy hô hấp ở trẻ sơ sinh. Từ đó đến nay, NCPAP được sử dụng ngày càng rộng rãi và góp phần đáng kể trong lĩnh vực hồi sức hô hấp trẻ sơ sinh và trẻ em. Dựa theo phương pháp tạo áp lực dương, CPAP được chia thành CPAP dòng thay đổi và CPAP dòng liên tục (trong đó có CPAP qua van Benveniste cải tiến). Van Benveniste gồm hai ống được đặt đồng trục với nhau và không nối liền nhau, giữa hai ống là một vòng có lố để thoát khí. So với van Benveniste thông thường, van Benveniste cải tiến cũng hoạt động dựa trên định luật Venturi nhưng có ưu điểm là cho phép đo áp lực một cách liên tuc.

Trong thời gian từ $7 / 2020$ đến $6 / 2021$, chúng tôi ghi nhận được 31 trường hợp trẻ bị suy hô hấp phải thở NCPAP. Tuổi trung bình là $3.84 \pm$ 2.51 tháng, thấp nhất là 1 tháng, lớn nhất là 11 tháng, trong đó hơn $80 \%$ trẻ ở lứa tuổi dưới 6 tháng. Phần lớn trẻ trong nghiên cứu của chúng tôi có biểu hiện suy hô hấp ngay từ những ngày đầu nhập viện và hơn một nửa trong số đó phải hỗ trợ bằng NCPAP trong vòng 4 ngày đầu kể từ khi phải thở oxi. Ở thời điểm trước khi thở NCPAP, tất cả trẻ đều có biểu hiện suy hô hấp với trên $90 \%$ số trẻ có ít nhất một trong các dấu hiệu thở nhanh, rút lõm lồng ngực, tím, kích thích hoặc li bì. Kết quả khí máu của những trẻ này cũng có biểu hiện giảm $\mathrm{PaO}_{2}$ và/ hoặc tăng $\mathrm{PaCO}_{2}$ kết hợp với toan hóa máu ở các mức độ với trên $50 \%$ số ca.

1. Kết quả điều trị chung. Tỉ lệ thành công của chúng tôi là $61.3 \%$, thấp hơn so với Machen và cộng sự là $71 \%^{2}$ và Trần Văn Trung là $73.6 \%{ }^{3}$. Số ngày thở NCPAP trung bình là 5.23 ngày, dài hơn so với Machen (3.12 ngày $)^{2}$ và Trần Văn Trung (4.15 ngày) ${ }^{3}$.

2. Sự thay đổi các chỉ số khí máu và triệu chứng lâm sang. Về khí máu, sự cải thiện tình trạng oxi hóa là rõ rệt nhất: $\mathrm{PaO}_{2}$ tăng từ $77.98 \mathrm{mmHg}$ lên $110.33 \mathrm{mmHg}, \mathrm{SaO}_{2}$ cũng tăng từ $87.67 \%$ lên $95.95 \%$. Sự thay đổi này cũng tương tự như kết quả nghiên cứu của Trần Văn Trung ${ }^{3}$. Tình trạng tăng $\mathrm{CO}_{2}$ máu được cải thiện không nhiều với mức giảm $\mathrm{PaCO}_{2}$ chỉ khoảng $5 \mathrm{mmHg}$ sau 6 giờ và không có ý nghĩa thống kê ( $p>0.05)$. Mức giảm $\mathrm{CO}_{2}$ tương tự cũng được Thia và cộng sự ghi nhận với $\mathrm{PaCO}_{2}$ giảm
$7 \mathrm{mmHg}(0.92 \mathrm{kPa})$ sau 12 giờ thở NCPAP trên đối tượng là trẻ dưới 1 tuổi bị viêm tiểu phế quản ${ }^{4}$. $\mathrm{pH}$ máu trung bình từ mức toan hóa (7.32) đã trở về mức bình thường (7.37), điều này cũng được chỉ ra trong nghiên cứu của Kinikar và cộng sự khi nghiên cứu trên 36 trẻ suy hô hấp trong đại dịch cúm $2009^{5}$.

Về lâm sàng, tî̉ lệ trẻ thở nhanh giảm một cách rõ rệt. Tác dụng làm giảm nhịp thở cũng đã được ghi nhận trong nhiêu nghiên cứu trước đây, Jayashree và cộng sự khi nghiên cứu trên 330 trẻ viêm phổi đã thấy rằng nhịp thở giảm khoảng 6 nhịp sau 2 giờ và khoảng 12 nhịp sau 6 giờ thở CPAP6. Tình trạng gắng sức cơ hô hấp cũng được cải thiện bằng việc giảm tỉ lệ trẻ có dấu hiệu rút lõm lồng ngực, tuy nhiên do đánh giá trong những giờ đầu nên tỉ lệ này giảm chưa nhiều. Hậu quả của suy hô hấp mà chủ yếu do tình trạng giảm oxy máu cũng được giải quyết thể hiện qua việc giảm rõ rệt tỉ lệ trẻ có dấu hiệu tím và biểu hiện thần kinh (kích thích hoặc li bi).

3. Các tai biến gặp khi thở NCPAP. Nghiên cứu của chúng tồi ghi nhận các tai biến do NCPAP là phù mặt và loét mữi. Các tai biến này chỉ gặp ở tỉ lệ thấp và mức độ nhẹ, không phải là nguyên nhân khiến bệnh nhân phải ngừng hỗ trợ bằng NCPAP. Nguyển nhân của các tai biến này thường do cố định gọng mũi quá chặt, có thể khắc phục dễ dàng bằng cố định lại gọng mũi cho phù hợp và chăm sóc tổn thương tại chố. Các tai biến nặng nề như tràn khí màng phổi hay tràn khí trung thất do thở áp lực cao không được ghi nhận trong nghiên cứu của chúng tôi.

\section{KẾT LUẬN}

Tỉ lệ thành công của thở NCPAP là $61.3 \%$.

Sau 6 giờ thở NCPAP, các chỉ số $\mathrm{PaO}_{2}, \mathrm{SaO}_{2}$, pH trong khí máu động mạch tăng rõ rệt, tỉ lệ trẻ có dấu hiệu rút lõm lî̀ng ngực, thở nhanh, tím và biểu hiện thần kinh (kích thích hoặc li bì) giảm một cách rõ rệt. Tuy nhiên chỉ số $\mathrm{PaCO}_{2}$ máu chỉ giảm nhẹ.

\section{TÀI LIẸU THAM KHẢO}

1. Friedman ML, Nitu ME. Acute Respiratory Failure in Children. Pediatr Ann. 2018;47(7):e268e273. doi:10.3928/19382359-20180625-01

2. Machen HE, Mwanza ZV, Brown JK, et al. Outcomes of Patients with Respiratory Distress Treated with Bubble CPAP on a Pediatric Ward in Malawi. J Trop Pediatr. 2015;61(6):421-427. doi:10.1093/tropej/fmv052

3. Trân Văn Trung (2009), Đánh giá hiệu quả của thở áp lực dương liên tục qua múi trong điều trị suy hô hấp do viểm phổi ở trẻ dưới 5 tuối tại bệnh viện Xanh Pôn, Trường Đại học Y Hà Nội. 
4. Thia LP, McKenzie SA, Blyth TP, Minasian CC, Kozlowska WJ, Carr SB. Randomised controlled trial of nasal continuous positive airways pressure (CPAP) in bronchiolitis. Arch Dis Child 2008;93(1):45-47. doi:10.1136/adc.2005.091231

5. Kinikar A, Kulkarni R, Valvi C, Gupte N. Use of indigenous bubble CPAP during swine flu pandemic in Pune, India. Indian J Pediatr. 2011;78(10):12161220. doi:10.1007/s12098-011-0389-X

6. Jayashree M, KiranBabu H, Singhi S, Nallasamy K. Use of Nasal Bubble CPAP in Children with Hypoxemic Clinical Pneumonia-Report from a Resource Limited Set-Up. J Trop Pediatr. 2016;62(1):69-74. doi:10.1093/ tropej/fmv063

\title{
KẾT QUẢ PHẪU THUÂT THAY KHỚP HÁNG NHÂN TAOO LOẠI CHUYỂN ĐộNG KÉP ĐIỀU TRI HOẠI TỬ VÔ KHUẨN CHỎM XƯƠ'NG ĐÙI
}

\author{
Nguyễn Tiến Dũng*, Trần Trung Dũng**, Vũ Trường Thịnh*
}

\section{TÓM TĂT}

Đă̆t vấn đề: Đánh giá kết phẫu thuật thay khớp háng toàn phần loại chuyển động kép điều trị hoại tử vô khuẩn chỏm xương đùi. Phương pháp: Nghiên cứu hồi cứu đánh giá trên 44 bệnh nhân thay 50 khớp toàn phần sử dung khớp háng nhân tao loại chuyển động kép để điều trị hoại tử vô khuẩn chỏm xương đùi ở Bệnh viên Viêt Đức từ tháng 7/2019 đến tháng 5/2021. Kết quả được đánh giá thông qua điểm HHS tỉ lệ trật sau mổ và mức độ hài lòng của bệnh nhân. Kết quả: Tuổi trung bình là 43,7 - 12,7 tuổi. 72,7\% bênh nhân là nam giới và $84,1 \%$ bênh nhân $\leq 55$ tuổi. 34 bệnh nhân $(77,3 \%)$ có tổn thương ở khớp háng 2 bên, 2 bênh nhân $(4,5 \%)$ tổn thương ở bên phải và 8 bệnh nhần $(18,2)$ tổn thương ở bên trái. Thời gian theo dõi trung bình là $14,9 \cdot 6,1$ tháng. Điểm HHS trước mổ và sau mổ lần lượt là 55.2 - $14.5,94.4$ • 15.4. Không có trường hợp nào gă̆p biến chứng nặng sau mổ như trật khớp, trật nội khớp, lỏng khớp hoặc mổ lại ở thời điểm theo dõi cuối cùng. $100 \%$ bệnh nhân hài lòng với cuộc mổ. Kết luân: Thay khớp háng toàn phần loại chuyển động kép để điều trị hoại tử vố khuẩn chỏm xương đùi mang lại kết quả tốt về chức năng khớp háng cũng như tỉ lệ trât sau mổ

Tư khoá: thay khớp háng toàn phần, khớp chuyển động kép, hoại tử vô khuẩn chỏm xương đùi, HHS,...

\section{SUMMARY}

OUTCOME OF PRIMARY TOTAL HIP

\section{ARTHROPLASTY USING MODULAR DUAL MOBILITY CUPS FOR OSTEONECROSIS OF THE HIP}

Introduction: Evaluation of the outcome of primary Total Hip Arthroplasty using modular dual mobility cups in treatment of hip osteonecrosis. Method: We retrospectively reviewed the outcome of 44 patients underwent 50 primary total hip arthroplasties using MDM cups in treatment of hip

\section{*Đại học Y Hà Nọi \\ **Đại học VinUniversity}

Chịu trách nhiệm chính: Nguyễn Tiến Dũng

Email: dung91295@gmail.com

Ngày nhận bài: 18.6.2021

Ngày phản biên khoa hoc: 16.8 .2021

Ngày duyệt bài: 16.8.2021 osteonecrosis in Viet Duc University Hospital between July 2019 and May 2021. The outcome was assessed by Harris Hip Score; dislocation rate and patient's satisfaction. Result: Mean age was 43,7 - 12,7 years old. $72,7 \%$ of the patients were males and $84,1 \%$ of the patients were less than or equal to 55 years old. There were 34 patients $(77,3 \%)$ had the condition on both leg; 2 patients $(4,5 \%)$ had affected right legs and the rest $8(18,2 \%)$ were left legs. Mean follow-up time was $13,9 \cdot 6,2$ months. Means pre-op HHS was 55.2 - 14.5 and post-op mean HHS was 94.4 - 15.4 There were no major complications such as dislocation; intraprosthesis dislocation, aseptic lossening or revision at latest follow up. $100 \%$ of the patients were satisfied with the procedure. Conclusion: Total hip arthroplasty with MDM cups for osteonecrosis of the hip yields good postoperative result in terms of hip function, dislocation rate.

Keyword: Total hip arthroplasty, MDM cups, osteonecrosis, HHS.

\section{I. ĐĂT VẤN ĐÊ}

Hoại tử vô khuẩn chỏm xương đùi là tình trạng bệnh lý xảy ra do sự tổn thương mạch nuôi của chỏm xương đùi do nguyên nhẩn chấn thương hoặc không chấn thương (lạm dụng corticoid, rượu bia, các bệnh lý toàn thân hoặc vô căn) dẫn đến thiếu máu, hoại tử, xẹp chỏm và biến dạng chỏm cũng như thoái hoá khớp háng. Bệnh thường gặp ở lứa tuổi từ 40 - 50 tuổi với nguyên nhân hàng đâu là lạm dụng corticoid và rượu bia ${ }^{1}$.Triệu chứng thường gặp và gây ảnh hưởng nhất của bệnh là đau, phù thuộc vào từng giai đoạn của bệnh mà triệu chứng đau có thể thay đổi từ đau lan toả, khổng liên quan đến vận động ở giai đoạn II do xương thiếu máu, hoai tử và bắt đầu tiêu, ở giai đoạn III khi bắt đầu xuất hiện võ xương dưới sụn, xẹp chỏm và ở giai đoạn IV khi khớp bị thoái hoá, triệu chứng đau biểu hiệu tình trạng thoái hoá khớp: đau liên tục, kể cả lúc ngủ, tăng lên khi vận động, bắt đâuu xuất hiện tự thế giảm đau, hạn chế vận động khớp và biến dạng khớp.

Bảng 1. Phân loại Ficat - Arlet và ARCO 